\title{
Alternative Heat Sink to Enhance Thermo-Hydraulic Behaviour of an Array of Short Pin Fins
}

\author{
Abhilash Maiti, B. V. S. S. S Prasad \\ Indian Institute of Technology, Madras \\ Chennai 600036, India \\ me15s001@smail.iitm.ac.in; prasad@iitm.ac.in
}

\begin{abstract}
Short pin fins are used at the trailing edge of the gas turbine blade for heat transfer augmentation. Accounting per unit mass heat transfer it is proposed to use slotted kidney shaped fins instead of solid cylindrical fins. Within fins a through slot is provided to allow the flow pass normal to the fins. The objective is (a) to increase heat transfer area, (b) reduce pressure drop and (c) decrease weight of the turbine blade. Solid cylindrical and solid kidney shaped; slotted cylindrical and slotted kidney shaped; staggered array geometries of ten rows having streamwise spacing and spanwise spacing of 2.5 times D (diameter of the fin) are placed between the uniform cross section channel. Thermo-hydraulic characteristics of the array geometries are compared within the channel Reynolds number range of 2,000 to 11,000. Numerical results are validated with the previously published experimental results. Pressure drop, local velocity, and total heat transfer values are computed and compared. Values of finwall and unfinned wall heat transfer rate are calculated for all the geometries. Among the array geometries, highest heat transfer rate is observed for slotted kidney shaped fin array. Heat sinks having slotted array geometry shows superior thermo-hydraulic behaviour compared to the corresponding solid fin array geometry. Numerical simulations were carried out using commercial software package ANSYS Fluent 15.0.
\end{abstract}

Keywords: trailing edge, gas turbine blade, short fins, slotted, kidney shaped

\section{Introduction}

Performance of the gas turbine engine depends upon the turbine inlet temperature. Higher the turbine inlet temperature, better is the cycle performance of the engine. Increase in the turbine inlet temperature results the blades being exposed to a higher heat flux. Hence cooling of the blades are very important to prolong its life. Turbine blades are cooled by the compressed air drawn after a few stages of the compressor. Since compressed air is supplied at the cost of cycle performance, design of efficient cooling technology is ever demanding.

Coolant encountering the leading edge region first; picks up the maximum amount of heat. By the time it reaches the trailing edge, the temperature increases significantly. Thus to cool the trailing edge region, heat transfer surface area is increased by implementing array of short pin fins. Since the fin array obstructs flow path of the coolant, significant amount of pressure drop is observed. So, in our present study it is proposed to use a modified array of fins which will reduce the pressure drop and enhance the heat transfer. Along with these two objectives, effort is also given to reduce weight of the fin array.

\subsection{Background}

Since last few decades researchers have studied overall heat transfer from finwall, unfinned surface and pressure drop across the different array configurations. Their main motive was to incorporate an optimal configuration that increases heat transfer and reduces pressure drop.

Metzger et al. [1] performed experiment using ten rows of short fins, arranged in a staggered configuration and found out the heat transfer, friction factor, row-wise Nusselt number. He stated a correlation that related Nusselt number with the row average Reynolds number and was as follows:

$$
\overline{\mathrm{Nu}}_{1-10}=0.069 * \overline{\mathrm{Re}}^{0.728} \text { for } \mathrm{X} / \mathrm{D}=2.5
$$


In other findings, Metzger et al. [2] experimentally established that by rotating the orientation of short cylindrical fin array geometry by $2 / 3$ rd value from inline to staggered arrangement, a $9 \%$ increase in heat transfer and $18 \%$ decrease in pressure drop was achieved. Prasad et al. [3] studied the conjugate effect of pressure drop and heat transfer in different body shapes: a) aerofoil NACA-0024, b) elliptical (1:2), c) elliptical (1:3), d) circular. They stated that among these geometries NACA-0024 aerofoil had superior thermo-hydraulic characteristics. Chyu et al. [4] reported that the convective heat transfer coefficient of finwall was $10 \%$ to $20 \%$ higher value than the unfinned surface. VanFossen [5] found out that short pin fins had a lower heat transfer rate than longer pin fins for a given flow condition. He also pointed out that the pin surface heat transfer coefficient was 35\% higher than the unfinned wall. Yao Peng [6] considered two array geometric configurations a) full-length fins between the plates, b) short length pin fins projected out from the plates. From his finding, he concluded that the short length fins reduced the pressure drop and increased the heat transfer; but fins that were too short were undesirable. Baruah et al. [7] studied heat transfer and pressure drop across an array of perforated elliptical fin array having three holes along the flow direction. They compared their result with solid elliptical fin array and stated that the pressure drop deceased by $12 \%$ and the heat transfer increased by $5.6 \%$. Similar approach with a square fin and a cylindrical fin in an array having a single hole within was studied separately by Manay et al. [8] and Dhumne et al. [9] with different clearance values between the fin top and channel.

Foregoing literature review reveals that, high heat transfer rate with low pressure drop and low weight can be achieved using perforated fin array. However very less effort has been given to find the maximum heat transfer rate using minimum mass of the heat sink. So our present study focuses in estimating the heat transfer rate and pressure drop from potential modified short pin fin array capable of transferring more heat per unit weight than traditionally used heat sinks.

\subsection{Physical Model}

Three dimensional computational domain is considered in our present study. Maintaining the domain invariant, fin geometries are varied from case to case. Ten rows of fins are arranged in a staggered pattern and are mounted between the two plates as shown in the fig. 2. Top view and the front view of the computational domain is shown in the fig. 1 , fig. 2 respectively. Entrance length and exit length of $127 \mathrm{~mm}$ and $67 \mathrm{~mm}$ respectively are not shown for the clarity of the figures. Sufficient entrance length ensures the flow to develop fully before it encounters the first row of the fins, whereas enough exit length reduces the back flow.

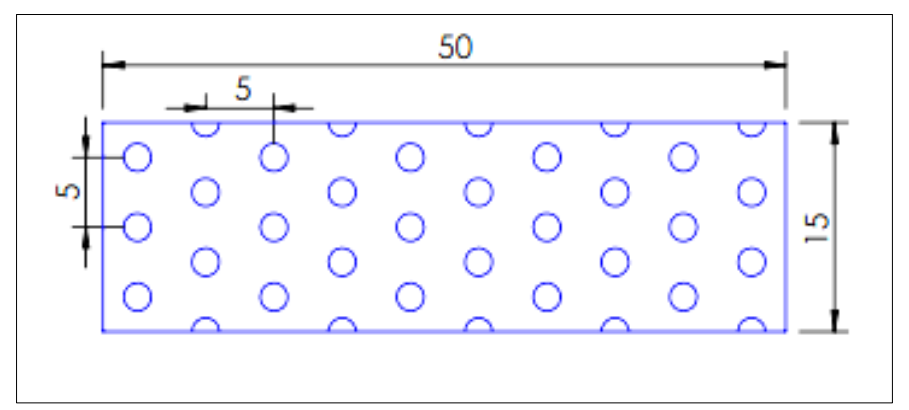

Fig. 1: Top view of the test section .

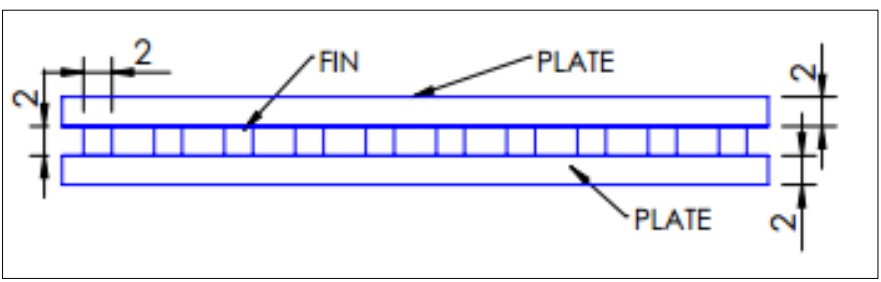

Fig. 2: Front view of the test section. 


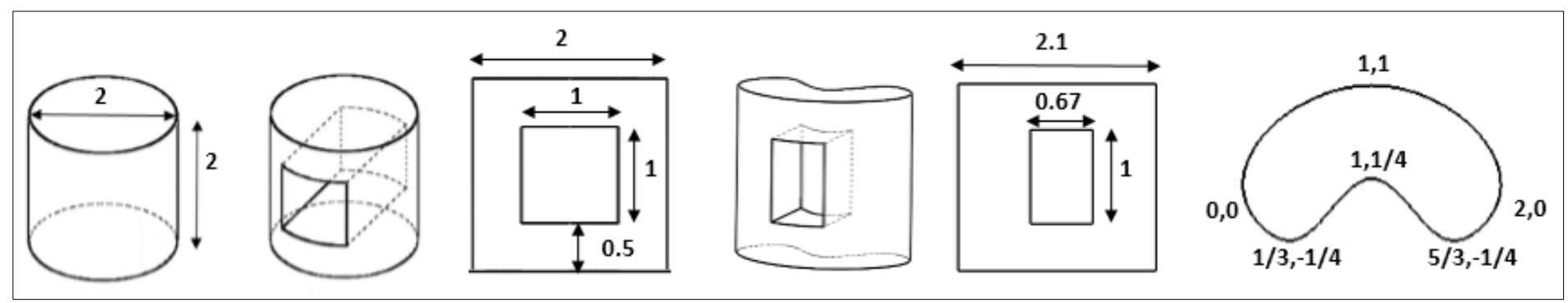

Fig. 3: 3D view and dimensions of the different fins geometries.

Shapes and dimensions of the fins used in our present study are shown in the fig. 3. Kidney shaped geometry is obtained by joining the shown co-ordinates with the help of a spline curve.

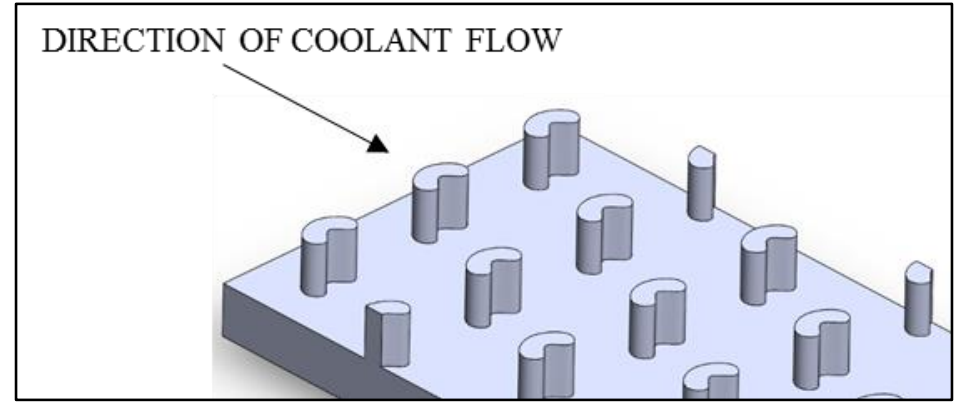

Fig. 4: Direction of coolant flow.

Orientation of the kidney shaped fins and the direction of coolant flow is shown in the fig. 4. Chosen configuration ensures maximum exposure of the frontal area of the finwall surface towards upstream direction of the coolant flow with negligible variation in the pressure drop.

\subsection{Grid Generation and Grid Independence Study}

Table 1: Grid Independence Study.

\begin{tabular}{|c|c|c|c|c|c|c|}
\hline \multicolumn{7}{|c|}{ SOLID } \\
\hline \multicolumn{4}{|c|}{ KIDNEY SHAPED } & \multicolumn{3}{|c|}{ CYLINDRICAL } \\
\hline Sl. No. & No. of cells & Heat Flux $\left(\mathrm{W} / \mathrm{m}^{2}\right)$ & $\%$ change & No. of cells & Heat Flux $\left(\mathrm{W} / \mathrm{m}^{2}\right)$ & $\%$ change \\
\hline 1 & 2292742 & 9732.27 & & 949967 & 9374.54 & \\
\hline 2 & 3543864 & 9849.38 & 1.20 & 1438275 & 9522.54 & 1.55 \\
\hline 3 & 5348593 & 9927.18 & 0.78 & 2202807 & 9634.21 & 1.16 \\
\hline \multicolumn{7}{|c|}{ SLOTTED } \\
\hline \multicolumn{4}{|c|}{ KIDNEY SHAPED } & \multicolumn{3}{|c|}{ CYLINDRICAL } \\
\hline 1 & 2344828 & 9879.62 & & 2481335 & 10123.2 & \\
\hline 2 & 3600313 & 10103.3 & 2.26 & 3257304 & 10373.9 & 2.42 \\
\hline 3 & 5554918 & 10138.1 & 0.34 & 5253194 & 10465.6 & 0.88 \\
\hline
\end{tabular}

The computational domains are meshed using commercial software ANSYS meshing tool 15.0. To resolve the heat transfer and flow phenomena precisely, finer mesh is created at the proximity of the fin and the boundary region. Areaweighted heat flux is used as a criteria for grid independence study. For all the domains, mesh size is repeatedly refined by a factor of 1.5 times the former, unless the percentage change in heat flux becomes approximately $1 \%$ to $2 \%$. The study of the grid independence test is shown in the tabular form in table 1. From the preformed grid independent study, domains 
having approximately 14 lakhs, 33 lakhs, 35 lakhs and 36 lakhs of cells are chosen finally for solid cylindrical, slotted cylindrical, solid kidney shaped and slotted kidney shaped fin arrays respectively for further studies.

\subsection{Boundary Condition}

Symmetric boundary condition is used at the two lateral sides of the flow domain to reduce the computational domain size; resulting decrease in the numerical simulation time. 'Absolute velocity' and 'outflow' boundary conditions are used at the inlet and outlet respectively. Constant temperature of $320 \mathrm{~K}$ is imposed on the top and bottom plate surface to find out the finwall, unfinned wall and total array heat transfer rate for different Reynolds number. 'Coupled boundary' is used at the solid-fluid interaction surface to ensure the continuous flow of heat from the solid surface to the flowing coolant. Coolant inlet temperature used in our present study is $300 \mathrm{~K}$. This ensures a temperature difference of $20 \mathrm{~K}$ between the coolant and plate at the entrance of the fin array, though this difference gradually decreases as it approaches to the downstream of the fin array.

\subsection{Governing Equations}

The foremost step in any numerical study is to determine the governing equations to solve the problem. In our present study, three-dimensional continuity, momentum and energy equations are solved to predict the thermo-hydraulic behaviour of the different fin array geometries. Constant pressure, steady state, $\mathrm{k}-\varepsilon$ realizable turbulence model is used. Since it is a steady state problem, time dependent terms are neglected from the governing equations.

For better accuracy, double precision is considered to solve the governing equations. Default under-relaxation factors: pressure 0.3 , density 1 , body forces 1 , momemtum 0.6 , turbulent kinetic energy 0.7 are used. Residual convergence is checked and monitored. When all the convergence parameters such as, continuity $1 \times 10^{-3}$, x-momentum $1 \times 10^{-3}$, ymomentum $1 \times 10^{-3}$, z-momentum $1 \times 10^{-3}$,energy $1 \times 10^{-6}, \mathrm{k} 1 \times 10^{-3}, \varepsilon 1 \times 10^{-3}$ are satisfied, the solution is convered.

\section{Results}

Validation

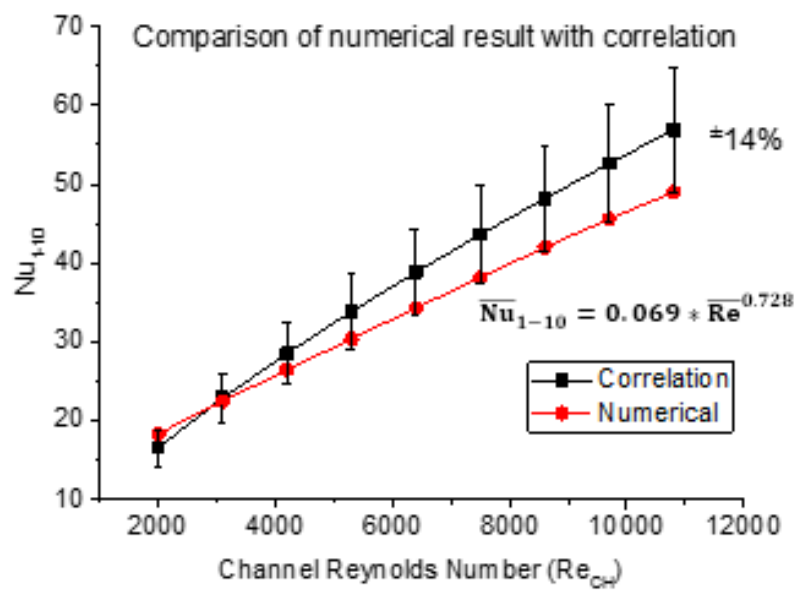

Fig. 5: Validation of numerical result with the correlation.

Figure 5 shows the validation of the numerical result with the correlation given by Metzger et al. [1] Eq. (1) for ten rows of solid cylindrical short fins arranged in staggered configuration. Good agreement between the two gives the confidence to use the same model to simulate for slotted cylinder, solid kidney shaped and slotted kidney shaped array configurations.

Total array heat transfer rate, finwall and unfinned wall heat transfer rate for different array configurations 


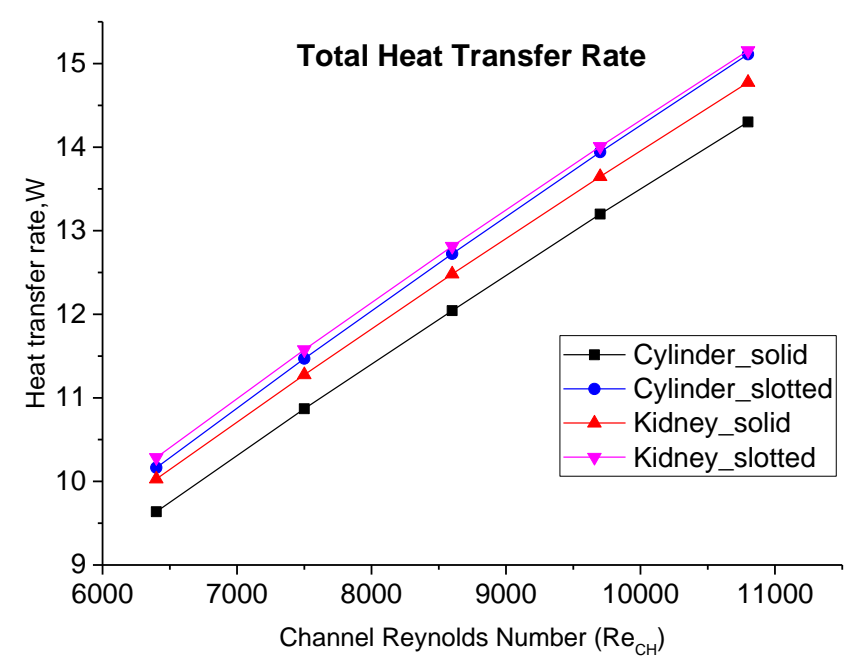

Fig. 6: Total heat transfer rate from different fin array geometries.

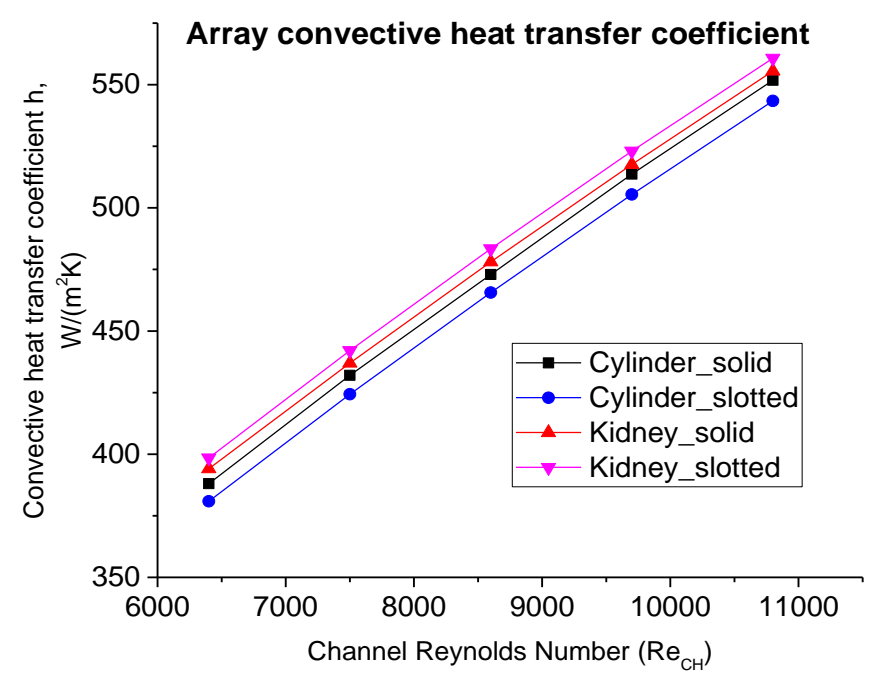

Fig. 7: Comparison of array convective heat transfer coefficient.

A comparison of 'total heat transfer rate' with increasing channel Reynolds number for different array geometries is shown in the fig. 6. It is observed that slotted fin array geometries have comparatively higher total heat transfer rate than their corresponding solid pin geometry due to higher wetted area. Among the four array geometries, slotted kidney shaped array has the highest heat transfer rate, followed by cylindrical slotted, kidney shaped solid and cylindrical solid array configuration. No significant change in the value of array convective heat transfer coefficient is observed between the respective array geometries as shown in fig. 7; but between the cylindrical and kidney shaped geometry, higher convective heat transfer coefficient is noticed in kidney shaped array due to higher value of average local velocity as shown in table 2. 


\section{Non-dimensional Heat flux contour}

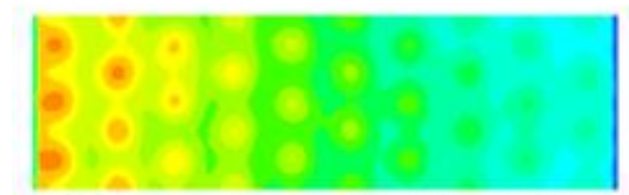

Heat flux from the plate of solid cylindrical fin array geometry

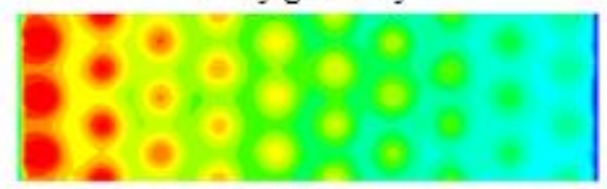

Heat flux from the plate of slotted cylindrical fin array geometry

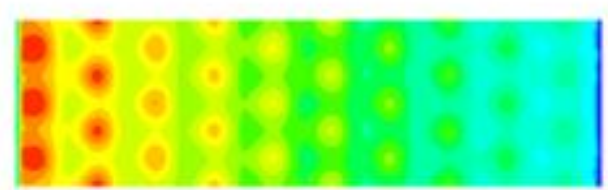

Heat flux from the plate of solid kidney shaped fin array geometry

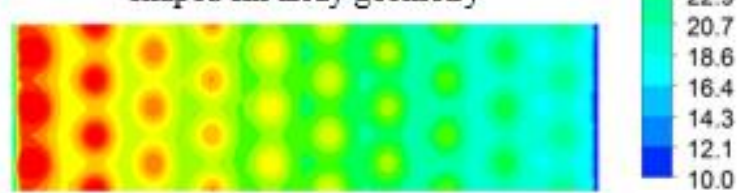

Heat flux from the plate of slotted kidney shaped fin array geometry

Fig. 8: Total heat flux from different array geometries for $\mathrm{Re}_{\mathrm{CH}}=6400$.

At the channel Reynolds number of 6400, non-dimensional heat flux contours on the plates are shown in the fig.8. From the fig. 8 it can also be concluded that for a given boundary condition, highest rate of 'total heat transfer' is observed in slotted kidney shaped fin followed by the sequence as mentioned earlier in fig. 6 .

Table 2: Numerical comparison of row-wise area average local velocity and pressure drop across different array geometries.

\begin{tabular}{|c|c|c|c|c|c|c|c|c|}
\hline \multirow{2}{*}{$\begin{array}{c}\text { Channel } \\
\text { Number }\end{array}$} & \multicolumn{4}{|c|}{ Cylindrical fin array } & \multicolumn{4}{c|}{ Kidney shaped fin array } \\
\cline { 2 - 9 } & \multicolumn{2}{|c|}{$\begin{array}{c}\text { Average local velocity } \\
(\mathrm{m} / \mathrm{s})\end{array}$} & \multicolumn{2}{|c|}{$\begin{array}{c}\text { Pressure drop } \\
(\mathrm{Pa})\end{array}$} & \multicolumn{2}{|c|}{$\begin{array}{c}\text { Average local velocity } \\
(\mathrm{m} / \mathrm{s})\end{array}$} & \multicolumn{2}{c|}{$\begin{array}{c}\text { Pressure drop } \\
(\mathrm{Pa})\end{array}$} \\
\cline { 2 - 9 } & solid & slotted & solid & slotted & solid & Slotted & solid & slotted \\
\hline 2000 & 13.63 & 11.69 & 472.84 & 325.15 & 14.34 & 12.74 & 625.63 & 497.69 \\
\hline 3100 & 21.15 & 18.16 & 1028.68 & 697.44 & 22.25 & 19.77 & 1362.89 & 1123.39 \\
\hline 4200 & 28.69 & 24.62 & 1762.76 & 1195.51 & 30.18 & 26.82 & 2371.82 & 1971.16 \\
\hline 5300 & 36.26 & 31.13 & 2661.37 & 1859.93 & 38.14 & 33.89 & 3634.54 & 3020.79 \\
\hline 6400 & 43.82 & 37.62 & 3713.62 & 2641.74 & 46.09 & 40.94 & 5136.84 & 4261.84 \\
\hline 7500 & 51.38 & 44.12 & 4878.48 & 3529.62 & 54.04 & 48.00 & 6882.18 & 5689.92 \\
\hline 8600 & 58.94 & 50.62 & 6162.35 & 4517.54 & 62.00 & 55.06 & 8861.33 & 7297.37 \\
\hline 9700 & 66.52 & 57.14 & 7623.57 & 5605.70 & 69.97 & 62.14 & 11072.80 & 9082.36 \\
\hline 10800 & 74.04 & 63.64 & 9122.02 & 6775.22 & 77.92 & 69.19 & 13500.34 & 11028.14 \\
\hline
\end{tabular}

For different channel Reynolds number, average of all the local velocity at the minimum cross-sectional area of flow at each row, is shown in the tabulation form. In the fin region of any row, slotted fin array geometries have higher maximum flow cross-sectional and hence low local velocity is observed in comparison to corresponding solid fin arrays. Slots provided within the fins result in more flow area. Between the cylindrical and kidney shaped geometry, higher average local velocity is observed in the latter case. This is because the width of cylindrical shaped fin is $2 \mathrm{~mm}$ whereas kidney shaped fin is $2.1 \mathrm{~mm}$ which is formed by joining the coordinates with a spline curve as shown in fig. 3. Lower average local velocity results in less pressure drop across the fin array as evident from the table 2. 


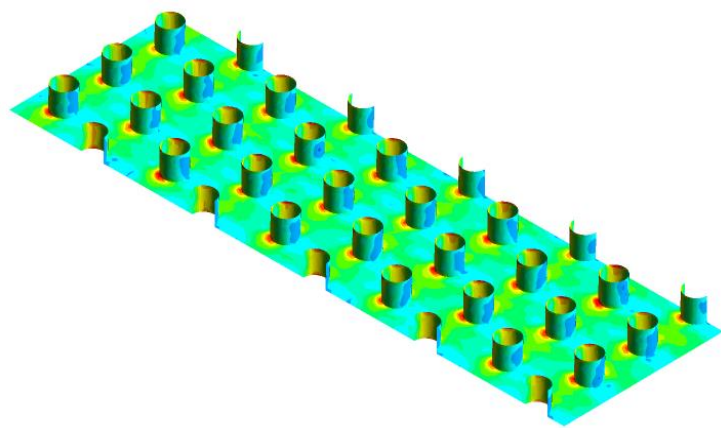

Fig. 9: $y+$ value of solid cylindrical pin fin array.

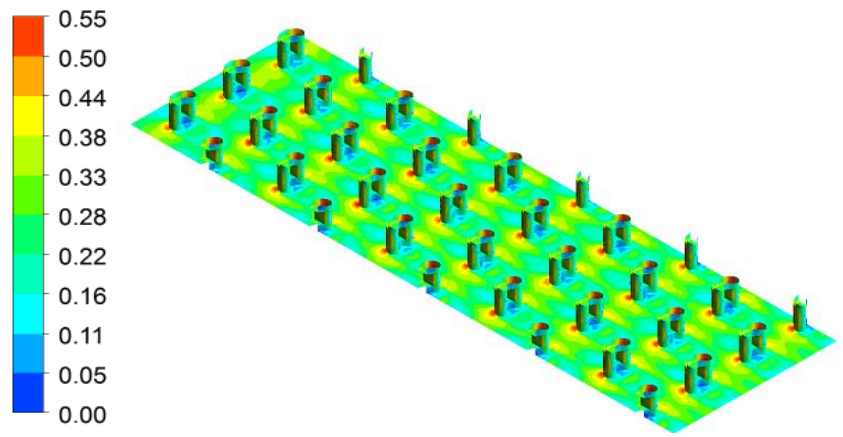

Fig. 10: $y+$ value of slotted kidney shaped pin fin array.

Table 3: $y+$ value for different pin fin array geometries.

\begin{tabular}{|c|c|c|c|c|c|}
\hline Fin array & No. of cells & Maximum y+ value & Fin array & No. of cells & Maximum y+ value \\
\hline Cylindrical solid & 1438275 & 0.89 & Kidney shaped solid & 3543864 & 0.78 \\
\hline $\begin{array}{c}\text { Cylindrical } \\
\text { slotted }\end{array}$ & 3257304 & 0.63 & Kidney shaped slotted & 3600313 & 0.66 \\
\hline
\end{tabular}

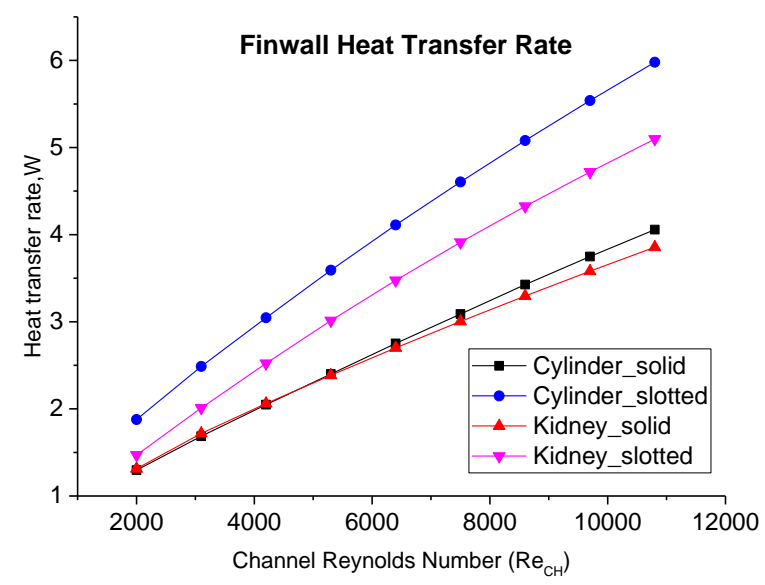

Fig. 11: Finwall region heat transfer rate comparison.

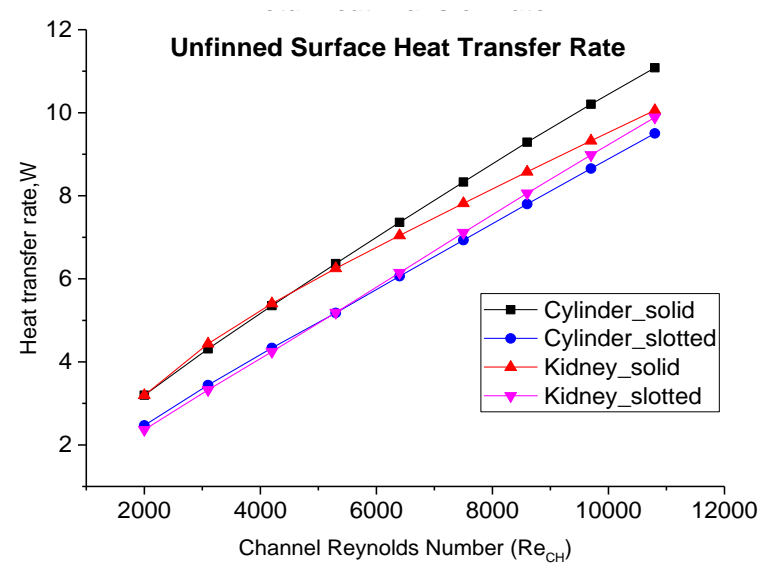

Fig. 12: Unfinned region heat transfer rate comparison. 
The $y+$ values of the solid cylindrical fin array and the slotted kidney shaped array geometries are shown in the fig. 9 , fig. 10 respectively. All the array geometries are numerically simulated using realizable k- $\varepsilon$ turbulence model with enhanced wall function. Finer mesh generated at the proximity of the fin arrays ensured correct capture of heat and fluid flow phenomenon. It is observed from the fig. 9, fig. 10 and table 3 that the maximum value of $y+$ in all the cases is within 1 .

Finwall and unfinned surface heat transfer rate is computed for the mentioned array geometries with increasing Reynolds number and their variation is shown in the fig. 11, fig. 12 respectively. With the increase in Reynolds number a diverging trend is observed between the respective solid and slotted fin arrays in the finwall region. This indicates that with increasing Reynolds number slotted fin configuration transfers more heat than solid fin array in the finwall region. Among the four configurations, slotted cylindrical finwall region has the highest heat transfer rate due to its largest finwall area followed by slotted kidney shaped, solid cylindrical and solid kidney shaped geometries. In the unfinned region, with increasing Reynolds number a constant heat transfer rate difference is observed in the cylindrical fin array, whereas a convergent pattern is noticed in the kidney shaped fin array. In a broader view, it can be concluded that with changing Reynolds number, in the endwall region insignificant change in the heat transfer rate between solid and slotted fin array geometries is observed.

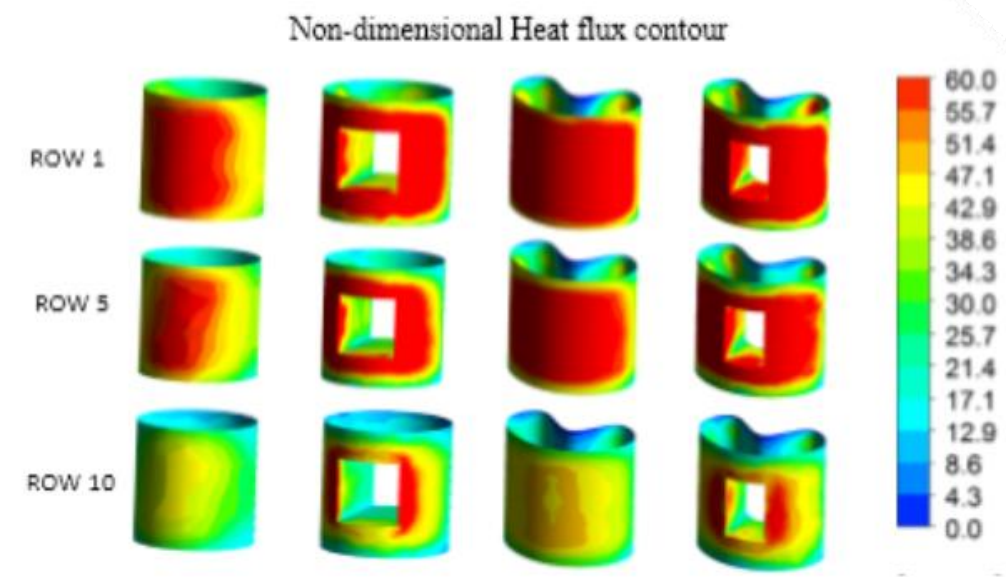

Fig. 13: Non-dimensional finwall heat flux at $\mathrm{Re}_{\mathrm{CH}=} 6400$.

In the fig.13 for a channel Reynolds number of 6400, non-dimensional finwall heat flux contours are shown for different array geometries placed in row 1, row 5 and row 10. Though the highest value of finwall heat transfer rate is observed in slotted cylindrical fin array (fig. 11), from the heat flux contour plot (fig. 13) it is observed that at the downstream the slotted cylindrical fin is ineffective when compared with the slotted kidney shaped fin.

\section{Conclusion}

Conclusions that can be drawn from our present study are as follows:

1. Maximum value of 'total array heat transfer rate' is observed for slotted kidney shaped fin array geometry.

2. Higher heat transfer rate and lower pressure drop is observed in slotted fin array geometry than its corresponding solid fin array geometry. Thus slotted fin array geometries can be used as an alternative heat sink at the trailing edge of the gas turbine blade to enhance heat transfer and reduce the pumping power of the coolant.

\section{References}

[1] D. E. Metzger, R. A. Berry, and J. P. Bronson, "Developing Heat Transfer in Rectangular Ducts With Staggered Arrays of Short Pin Fins," J. Heat Transfer, vol. 104, no. 4, pp. 700-706, 1982.

[2] D. E. Metzger, C. S. Fan, and S. W. Haley, "Effects of Pin Shape and Array Orientation on Heat Transfer and Pressure Loss in Pin Fin Arrays," J. Eng. Gas Turbines Power, vol. 106, no. 1, pp. 252-257, 1984.

[3] A. A. T. and V. R. M. R. B.V.S.S.S. Prasad, "HEAT TRANSFER FROM AEROFOILS IN CROSS-FLOW," Pergamon Press Ltd., vol. 6, pp. 879-890, 1992. 
[4] M. K. Chyu, Y. C. Hsing, T. I.-P. Shih, and V. Natarajan, "Heat Transfer Contributions of Pins and Endwall in PinFin Arrays: Effects of Thermal Boundary Condition Modeling," J. Turbomach., vol. 121, no. 2, pp. 257-263, 1999.

[5] G. J. VanFossen, "Heat-Transfer Coefficients for Staggered Arrays of Short Pin Fins," J. Eng. Power, vol. 104, no. April 1982, pp. 268-274, 1982.

[6] Y. Peng, "Heat Transfer and Friction Loss Characteristics of Pin Fin Cooling Configurations," J. Eng. Gas Turbines Power, vol. 106, no. 1, pp. 246-251, 1984.

[7] M. Baruah, A. Dewan, and P. Mahanta, "Performance of Elliptical Pin Fin Heat Exchanger with Three Elliptical Perforations," CFD Lett., vol. 3, pp. 65-73, 2011.

[8] E. Manay, "3D NUMERICAL SIMULATION OF HEAT TRANSFER FROM PIN-FINS," Int. Res. J. Mech. Eng., vol. 1, no. 1, pp. 1-15, 2014.

[9] A. B. Dhumne and H. S. Farkade, "Heat Transfer Analysis of Cylindrical Perforated Fins in Staggered Arrangement," Int. J. Innov. Technol. Explor. Eng., vol. 2, no. 5, pp. 225-230, 2013.

\section{Nomenclature}

A Cross section of the channel, $\mathrm{m}^{2}$

$\mathrm{A}_{\mathrm{s}} \quad$ Total wetted surface area for heat transfer,

$\mathrm{m}^{2}$

A finned Total finned surface area, $\mathrm{m}^{2}$,

$$
=\pi * \mathrm{D} * \mathrm{H} * \mathrm{n}
$$

A unfinned Total unfinned surface area, $\mathrm{m}^{2}$

$=A_{s}-A_{\text {finned }}$

D Diameter of the pin fin, $m$

$\mathrm{D}_{h} \quad$ Hydraulic diameter of the channel, $\mathrm{m}$,

$$
=\frac{4 \mathrm{~A}}{\mathrm{P}}
$$

$\mathrm{H} \quad$ Height of the fins, $\mathrm{m}$

$\mathrm{k}$ Thermal conductivity of the coolant, W/m-

$\mathrm{K}$

$\overline{\mathrm{Nu}}_{1-10} \quad$ Average Nusselt number for ten rows

$$
=\frac{\overline{\mathrm{h}} \mathrm{D}}{\mathrm{k}}
$$

n Total number of pins

P Wetted perimeter of the channel, $\mathrm{m}$
$\Delta \mathrm{P} \quad$ Pressure drop, $\mathrm{Pa}$

Q Total heat transfer from the array, W

$\mathrm{Re}_{\mathrm{CH}} \quad$ Channel Reynolds number

$$
=\frac{\rho * V_{\text {in }} * D_{h}}{\mu}
$$

$V_{\text {avg }} \quad$ Average of maximum local velocity within ten rows of fins, $\mathrm{m} / \mathrm{s}$

Greek Letters

$\rho \quad$ Density of coolant air, $\mathrm{kg} / \mathrm{m} 3$

$\mu \quad$ Dynamic viscosity of coolant air, N-s/m2

Suffix

avg Average

$\mathrm{CH}$ Channel

D Diameter of the fin

finnedFinned

h Hydraulic

s Surface area

unfinned Unfinned 